Article

\title{
Low-Temperature Vapor-Phase Synthesis of Single-Crystalline Gold Nanostructures: Toward Exceptional Electrocatalytic Activity for Methanol Oxidation Reaction
}

\author{
Siyeong Yang ${ }^{1}$, Kkotchorong Park ${ }^{1}$, Bongsoo Kim ${ }^{1, *}$ and Taejoon Kang ${ }^{2,3, *}$ \\ 1 Department of Chemistry, KAIST, Daejeon 34141, Korea; yy1633@kaist.ac.kr (S.Y.); \\ smile_cho@kaist.ac.kr (K.P.) \\ 2 Bionanotechnology Research Center, KRIBB, Daejeon 34141, Korea \\ 3 Department of Nanobiotechnology, KRIBB School of Biotechnology, UST, Daejeon 34113, Korea \\ * Correspondence: bongsoo@kaist.ac.kr (B.K.); kangtaejoon@kribb.re.kr (T.K.)
}

Received: 9 March 2019; Accepted: 6 April 2019; Published: 10 April 2019

\begin{abstract}
Au nanostructures (Au NSs) have been considered promising materials for applications in fuel cell catalysis, electrochemistry, and plasmonics. For the fabrication of high-performance Au NS-based electronic or electrochemical devices, Au NSs should have clean surfaces and be directly supported on a substrate without any mediating molecules. Herein, we report the vapor-phase synthesis of Au NSs on a fluorine-doped tin oxide (FTO) substrate at $120^{\circ} \mathrm{C}$ and their application to the electrocatalytic methanol oxidation reaction (MOR). By employing $\mathrm{AuCl}$ as a precursor, the synthesis temperature for $\mathrm{Au}$ NSs was reduced to under $200^{\circ} \mathrm{C}$, enabling the direct synthesis of $\mathrm{Au}$ NSs on an FTO substrate in the vapor phase. Considering that previously reported vapor-phase synthesis of $\mathrm{Au}$ NSs requires a high temperature over $1000^{\circ} \mathrm{C}$, this proposed synthetic method is remarkably simple and practical. Moreover, we could selectively synthesize Au nanoparticles (NPs) and nanoplates by adjusting the location of the substrate, and the size of the Au NPs was controllable by changing the reaction temperature. The synthesized Au NSs are a single-crystalline material with clean surfaces that achieved a high methanol oxidation current density of $14.65 \mathrm{~mA} / \mathrm{cm}^{2}$ when intimately supported by an FTO substrate. We anticipate that this novel synthetic method can widen the applicability of vapor-phase synthesized Au NSs for electronic and electrochemical devices.
\end{abstract}

Keywords: low temperature; vapor-phase synthesis; Au nanostructures; electrocatalyst; methanol oxidation reaction

\section{Introduction}

Au nanostructures (Au NSs) have been widely used for applications in electronics, electrochemistry, plasmonics, biomedical sensing, etc. [1-5]. In particular, Au NSs have been considered promising catalysts for the methanol oxidation reaction (MOR) because Au NSs do not form poisoning intermediates during electrocatalytic reactions [6-9]. Therefore, various kinds of Au NSs have been synthesized and applied to electrocatalytic reactions to improve catalytic activities [10-13]. According to previous studies, the intrinsic properties of Au NSs, such as their size, shape, and lattice plane, highly influence the catalytic activity of Au NSs [14-17]. In addition, the interface structure between $\mathrm{Au}$ NSs and the supporting electrode is critical to the improvement of the electrocatalytic activity since the interface structure significantly affects electron transfer from Au NSs to the conductive substrate and vice versa [18-20]. Moreover, clean Au NS surfaces are important to increase the number of effective collisions between reactants and catalytic active sites on the Au NS surface [21-24]. Thus, 
an ideal electrocatalytic Au NS should have a well-defined morphology, crystallinity, clean surfaces, and direct interface with a substrate.

For the synthesis of Au NSs, solution-phase synthetic methods have been commonly employed because these methods enable large-scale synthesis of Au NSs and control of the NS morphology by using ligand molecules [25-27]. However, ligand molecules often inhibit the catalytic activity of Au NSs since ligand molecules can interrupt electron transfer and collision with reactants [23,28-31]. In addition, the agglomeration of Au NSs can also lower the efficiency of catalytic reactions [32-34]. Recently, vapor-phase synthesis of Au NSs has emerged as a promising synthesis technique because vapor-phase synthetic methods can produce surfactant-free, single-crystalline, ultraclean, ultraflat, and morphology-tunable Au NSs [35-39]. Although the Au NSs synthesized in a vapor phase exhibit excellent physicochemical properties, they have rarely been applied to electrocatalytic reactions because vapor-phase-grown Au NSs are mainly deposited on nonconductive and temperature-stable substrates. The vapor-phase growth temperature of Au NSs is high (over $1000^{\circ} \mathrm{C}$ ) and, thus, versatile electrically conductive substrates, such as indium tin oxide and fluorine doped tin oxide (FTO), cannot be utilized $[35,40]$. Some papers reported the lowed temperature (below $1000{ }^{\circ} \mathrm{C}$ ) $[41,42]$. While the adoption of an organometallic compound as a precursor allows a reaction temperature below $\sim 500{ }^{\circ} \mathrm{C}$, the decomposition of the organometallic compound generates byproducts that adsorb on the Au surfaces [43]. If we can routinely synthesize high-quality Au NSs on a conductive substrate in a vapor phase, the product may be a promising Au NS-based catalytic electrode.

Herein, we report a novel vapor-phase synthesis of Au NSs in the temperature range from 120 to $200{ }^{\circ} \mathrm{C}$ and the electrocatalytic MOR application of Au NSs. The use of $\mathrm{AuCl}$ as a precursor enabled an organic-molecule-free synthesis of Au NSs on an FTO substrate at low temperature. The synthetic reactions were investigated by X-ray photoelectron spectroscopy (XPS) analysis, which confirmed the disproportionation reaction of $\mathrm{AuCl}$. We found that Au nanoparticles (NPs) and nanoplates could be selectively synthesized depending on the location of the substrate, and the size of the Au NPs could be controlled by the reaction temperature. Importantly, Au NPs on an FTO substrate were employed as a catalytic electrode for the MOR, and the electrode exhibited a current density of $14.65 \mathrm{~mA} / \mathrm{cm}^{2}$, which is 33 times higher than that obtained with commercial Au NPs on an FTO substrate. This proposed vapor-phase synthetic method for Au NSs enables the direct growth of single-crystalline and clean $\mathrm{Au}$ NSs on a desired substrate and is a promising approach for the development of electrocatalysts and electrochemical sensing platforms based on Au NSs.

\section{Materials and Methods}

\subsection{Synthesis of Au NPs on an FTO Substrate}

The FTO coated glass slides, an electrically conductive substrate, were purchased from Sigma-Aldrich (No. 735159, Saint Louis, MO, USA). The FTO substrates were sonicated in acetone, ethanol, and water for $30 \mathrm{~min}$, washed with acetone, and dried by $\mathrm{N}_{2}$. To synthesize Au NPs on a clean FTO substrate, $1.5 \mathrm{mg}$ of fresh $\mathrm{AuCl}$ powder (99.9\%, Aldrich) was placed in the center of the heating zone in a furnace with a 1 inch diameter inner quartz tube, and an FTO substrate was placed 15-20 $\mathrm{mm}$ from the $\mathrm{AuCl}$ powder toward the downstream side. Next, the furnace was heated to the desired temperature and maintained for $30 \mathrm{~min}$ under a flow of $\operatorname{Ar}(150 \mathrm{sccm})$. The pressure of the chamber was 0.7 Torr.

\subsection{Synthesis of Au Nanoplates on an FTO Substrate}

The FTO substrates were sonicated in acetone, ethanol, and water for $30 \mathrm{~min}$, washed with acetone, and dried by $\mathrm{N}_{2}$. To synthesize Au nanoplates on a clean FTO substrate, $1.5 \mathrm{mg}$ of fresh $\mathrm{AuCl}$ powder was placed in the center of the heating zone in a furnace, and an FTO substrate was placed $3-5 \mathrm{~mm}$ from the $\mathrm{AuCl}$ powder toward the downstream side. Next, the furnace was heated to $200{ }^{\circ} \mathrm{C}$ and 
maintained at that temperature for 30 min under a flow of $\operatorname{Ar}(150 \mathrm{sccm})$. The pressure of the chamber was 0.7 Torr.

\subsection{Cyclic Voltammetry (CV) Measurements}

All electrochemical analyses were carried out in the ambient atmosphere using a three-electrode cell consisting of vapor-phase-grown Au NP/FTO or colloidal Au NP/FTO as the working electrode, $\mathrm{Pt}$ wire as the auxiliary electrode, and a saturated calomel electrode (SCE) as the reference electrode. For vapor-phase-grown Au NP/FTO, the FTO substrate was partially coated with an epoxy resin after the reaction in furnace system to prevent contact between the solution and the electrode clamp. The vapor-phase-grown Au NP/FTO electrode was prepared as described above. The colloidal Au NP/FTO electrode was prepared by dropwise evaporation of Au NPs stabilized suspension in citrate buffer (20 $\mathrm{nm}$, Aldrich) on an FTO substrate, rinsing with water, and drying with $\mathrm{N}_{2}$. The electrochemical active surface area of the Au NPs was measured in $3 \mathrm{~mL}$ of a $0.1 \mathrm{M} \mathrm{KOH}$ (Junsei, Tokyo, Japan) aqueous solution by cyclic scanning from -0.1 to $0.5 \mathrm{~V}$ (for vapor-phase Au NP/FTO) or $0.45 \mathrm{~V}$ (for colloidal Au NP/FTO) (vs. SCE, Rosemead, CA, USA). Before measurements, the $0.1 \mathrm{M} \mathrm{KOH}$ and methanol solutions were purged with $\mathrm{N}_{2}$ for $30 \mathrm{~min}$. The electrooxidation of methanol was measured by cyclic scanning from -0.15 to $0.5 \mathrm{~V}$ (vs. SCE).

\subsection{Instrumentation}

Field-emission scanning electron microscopy (SEM) images were obtained using a Nova 230 (CA, USA). Transmission electron microscopy (TEM) images, high-resolution TEM (HR-TEM) images, and electron diffraction patterns were taken on a TECNAI TF30 ST transmission electron microscope (Hilsboro, OR, USA) operated at $300 \mathrm{kV}$. X-ray diffraction (XRD) spectra were obtained with a D/MAX-2500 instrument (RIGAKU, Auburn Hills, MI, USA). The cross-sectional TEM image of the Au nanoplate was obtained using a Helios Nanolab 450 F1 microscope (FEI company, Hillsboro, OR, USA). X-ray photoelectron spectroscopy (XPS) spectra were obtained from K-alpha (Thermo VG Scientific, Waltham, MA, USA). Cyclic voltammetry (CV) was recorded using a computer-controlled CHI643B electrochemical analyzer (Austin, TX, USA).

\section{Results and Discussion}

Figure 1 is a schematic illustration of the vapor-phase synthesis of Au NSs. AuCl powder was placed in the heating zone of a horizontal quartz tube furnace system, and the FTO substrate was positioned 3-20 mm away from the $\mathrm{AuCl}$ powder. For the synthesis of Au NSs, the system was heated to $120-200{ }^{\circ} \mathrm{C}$ under an Ar gas flow of $150 \mathrm{sccm}$. The pressure of the chamber was maintained at 0.7 Torr. After reacting for $30 \mathrm{~min}$, single-crystalline Au NSs were obtained on an FTO substrate. As shown in Figure 1, we could synthesize single-crystalline Au nanoplates and Au NPs. The morphology can be controlled by adjusting the distance between the $\mathrm{AuCl}$ precursor and the FTO substrate. When the substrate was placed 15-20 mm away from the $\mathrm{AuCl}$, only $\mathrm{Au}$ NPs were grown on the substrate. When the substrate was closer $(3-5 \mathrm{~mm})$ to the precursor, Au nanoplates were obtained on the substrate. The previous literature suggested that the flux of the precursor can affect the morphology of noble metal NSs during vapor-phase growth [35]. In this experiment, the morphology of the Au NSs can also be controlled by the flux of the AuCl.

Au commonly exists in nature as $\mathrm{Au}^{0}, \mathrm{Au}^{1+}$, and $\mathrm{Au}^{3+}$ [44]. Previously, our group evaporated a Au slug $\left(\mathrm{Au}^{0}\right)$ at temperatures greater than $1000{ }^{\circ} \mathrm{C}$ and successfully synthesized several kinds of $\mathrm{Au}$ NSs [40]. Wang et al. employed $\mathrm{HAuCl}_{4}$, in which $\mathrm{Au}$ is in a +3 oxidation state, as a starting material for the vapor-phase synthesis of $\mathrm{Au}$ NSs [45]. Although the use of $\mathrm{HAuCl}_{4}$ lowered the reaction temperature to $\sim 500{ }^{\circ} \mathrm{C}$, the temperature was still too high for the synthesis of Au NSs on an FTO substrate. To synthesize $\mathrm{Au}$ NSs on an FTO substrate in a vapor phase, we used $\mathrm{AuCl}$ as a precursor because the disproportionation reaction of $\mathrm{AuCl}$ can occur under mild conditions [46-48]. As a result, single-crystalline Au NPs and nanoplates were successfully synthesized at temperatures below $200{ }^{\circ} \mathrm{C}$. 


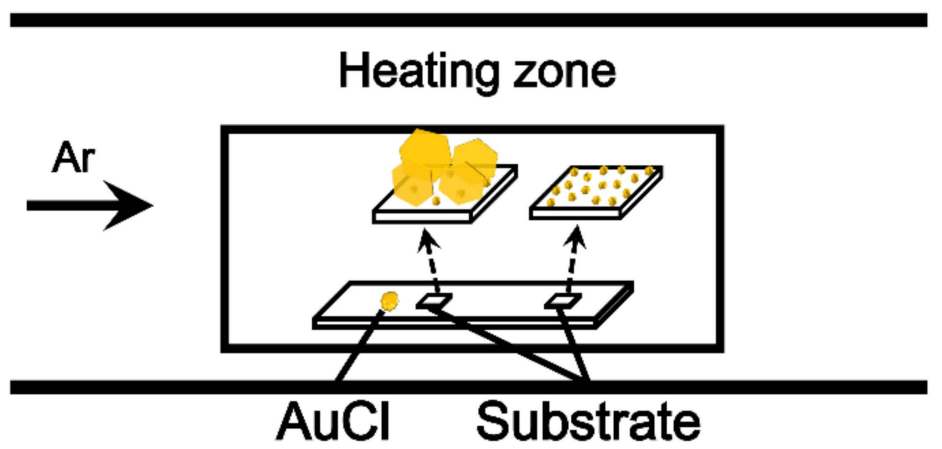

Figure 1. Schematic illustration of the vapor-phase synthesis of Au nanostructures (NSs) at low temperature. When the substrate was placed 15-20 mm away from $\mathrm{AuCl}, \mathrm{Au} \mathrm{NPs}$ were grown on the substrate. When the substrate was placed 3-5 mm away from $\mathrm{AuCl}$, Au nanoplates were obtained on the substrate.

To investigate whether $\mathrm{AuCl}$ disproportionated to produce metallic $\mathrm{Au}\left(\mathrm{Au}^{0}\right)$ during the experiment, we analyzed the XPS spectra of the substrates after chemically reacting in the experimental system. Figure 2 shows the XPS spectra obtained for the substrates placed in or out of the heating zone. Substrate A was positioned approximately $10 \mathrm{~mm}$ from the $\mathrm{AuCl}$ powder, and substrate B was positioned approximately $250 \mathrm{~mm}$ from the precursor (inset of Figure 2). For substrate A, only the binding energy peaks corresponding to metallic $\mathrm{Au}\left(\mathrm{Au}^{0}\right)$ were measured. For substrate $\mathrm{B}$, peaks corresponding to $\mathrm{Au}^{3+}$ and $\mathrm{Cl}$ were also observed [49,50]. The XPS results suggest that $\mathrm{AuCl}$ can supply $\mathrm{Au}$ atoms to substrate $\mathrm{A}$ by the disproportionation reaction of $\mathrm{AuCl}(3 \mathrm{AuCl} \rightarrow 2 \mathrm{Au}+$ $\left.\mathrm{AuCl}_{3}\right)[38,51]$. The resultant $2 \mathrm{Au}$ atoms $\left(\mathrm{Au}^{0}\right)$ were deposited on the FTO substrate immediately after the disproportionation reaction occurred because the reaction temperature of this synthetic method was below $200{ }^{\circ} \mathrm{C}$. The remaining $\mathrm{AuCl}_{3}$ vapor was carried by the carrier gas flow and condensed on substrate $\mathrm{B}$. This growth mechanism indicates that the amount of $\mathrm{Au}^{0}$ can be varied by changing the substrate location and the reaction temperature. Therefore, we could selectively synthesize $\mathrm{Au}$ NPs and nanoplates by adjusting the substrate location, and we could control the size of the NPs by changing the reaction temperature.

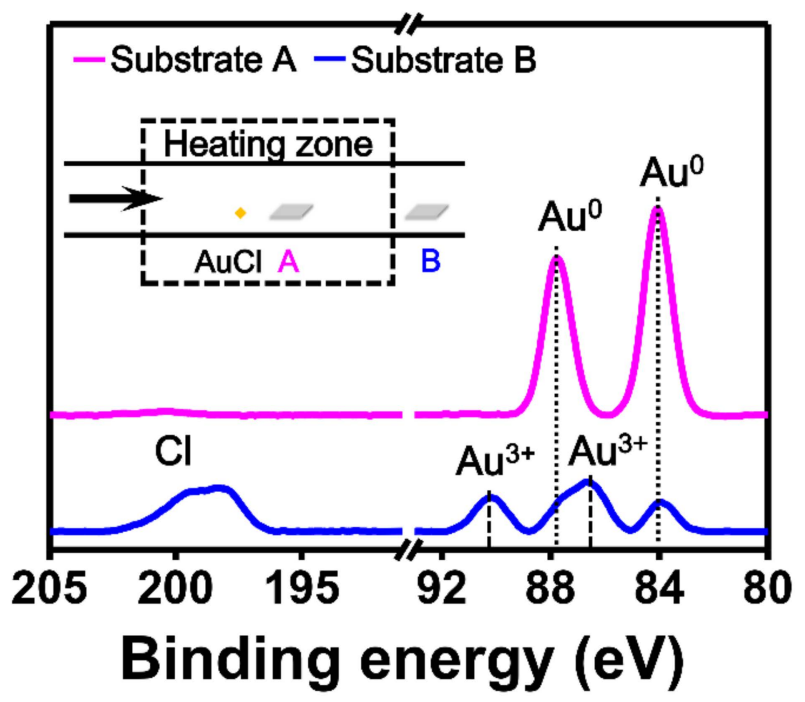

Figure 2. X-ray photoelectron spectroscopy (XPS) spectra obtained for two substrates placed in or out of the heating zone. Substrate A was positioned approximately $10 \mathrm{~mm}$ away from $\mathrm{AuCl}$, and substrate B was positioned approximately $250 \mathrm{~mm}$ away from the precursor (inset). The binding energy peaks corresponding to $\mathrm{Au}^{0}$ were measured on substrate $\mathrm{A}$ (magenta). Binding energy peaks corresponding to $\mathrm{Au}^{3+}$ and $\mathrm{Cl}$ were measured on substrate $\mathrm{B}$ (blue). 
Figure 3a shows SEM images of the Au NPs grown on FTO substrates. The as-synthesized Au NPs were well dispersed on the substrates without aggregation. The X-ray diffractogram also suggests that crystalline Au NSs were synthesized on an FTO substrate (Figure S1) [52]. Interestingly, the SEM images show that the size of the Au NPs increased as the reaction temperature increased. Figure $3 b$ is the plot of the average size of the Au NPs versus the reaction temperature. The average size of the Au NPs linearly increased from $23 \pm 3.9 \mathrm{~nm}$ to $36 \pm 4.2 \mathrm{~nm}, 44 \pm 4.7 \mathrm{~nm}$, and $59 \pm 5.3 \mathrm{~nm}$ as the reaction temperature increased from 120 to 150,170 , and $200{ }^{\circ} \mathrm{C}$, respectively. The linear fit line was determined to be $y=0.457 x-32.90$ with an $R^{2}$ value of 0.998 . As the reaction temperature increases, more of the $\mathrm{AuCl}$ precursor may be vaporized, and thus, a more concentrated AuCl vapor could be supplied to the substrate, leading to an increase in the Au NP size.
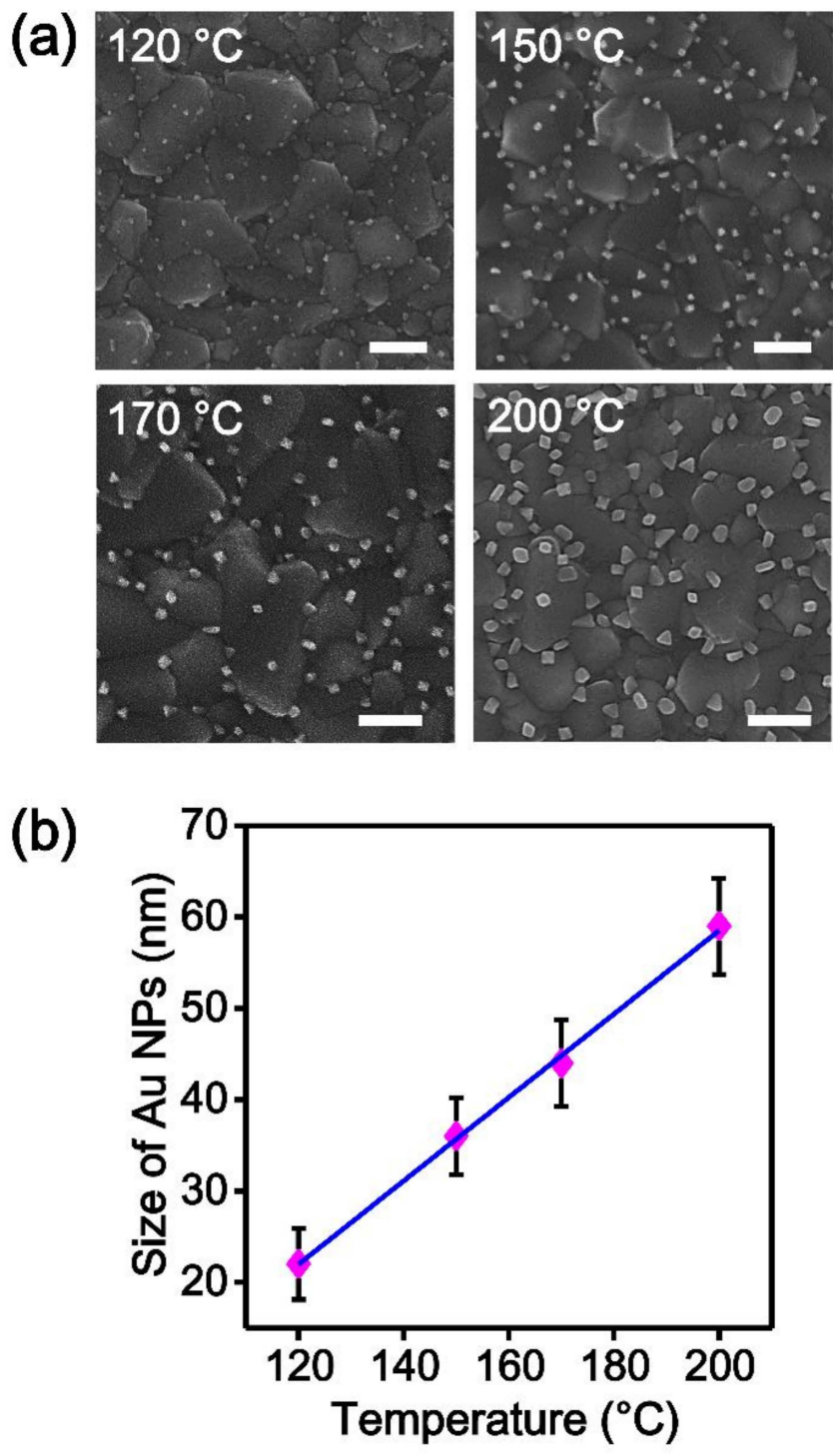

Figure 3. (a) Scanning electron microscopy (SEM) images of the Au nanoparticles (NPs) grown on fluorine-doped tin oxide (FTO) substrates. The size of the Au NPs increased as the reaction temperature increased from 120 to $200{ }^{\circ} \mathrm{C}$. Scale bar is $200 \mathrm{~nm}$. (b) Plot of the average size of the Au NPs versus the reaction temperature. The average size of the Au NPs increased from $23 \pm 3.9 \mathrm{~nm}$ to $36 \pm 4.2 \mathrm{~nm}, 44 \pm$ $4.7 \mathrm{~nm}$, and $59 \pm 5.3 \mathrm{~nm}$ with the increase in the reaction temperature. The linear fit line is also shown (blue). Data represent the mean plus standard deviation from twenty measurements. 
The Au NPs synthesized on an FTO substrate were further investigated by a TEM analysis. First, we obtained a cross-sectional HR-TEM image of a Au NP on an FTO substrate using focused ion beam milling (Figure 4a). The cross-sectional HR-TEM image clearly showed that the Au NP directly interfaced with the FTO substrate without any space. This perfect contact can ensure excellent electron- transfer between the Au NPs and the substrate [18,19]. We also obtained a TEM image of Au NPs that were detached from the substrate after sonication for $30 \mathrm{~min}$ (Figure $4 \mathrm{~b}-\mathrm{d}$ ). The HR-TEM analysis results suggested that the planes of the polyhedral Au NPs were uniformly enclosed by the $\mathrm{Au}$ (111) lattice plane. Moreover, the fast Fourier transformation (FFT) patterns clearly showed the single-crystalline nature of the Au NPs (insets of Figure 4c,d).

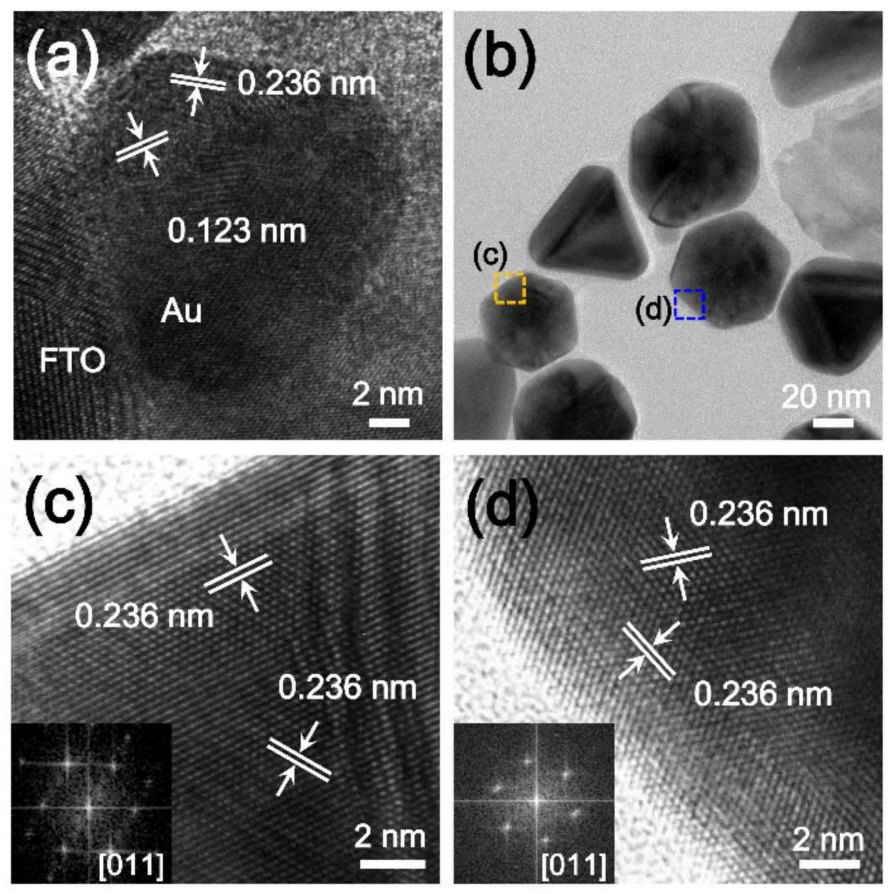

Figure 4. (a) Cross-sectional high-resolution transmission electron microscopy (HR-TEM) image of Au NPs on an FTO substrate. The Au NPs directly interfaced with the FTO substrate without any space; (b) TEM image of Au NPs detached from the FTO substrate; (c,d) HR-TEM images of Au NPs obtained from the (c) orange and (d) blue boxes of (b). Insets are fast Fourier transformation (FFT) patterns of the Au NPs.

Figure 5a shows the SEM image of free-standing Au nanoplates synthesized on an FTO substrate. The Au nanoplates were densely grown on the substrate and have well-defined shapes. The TEM image and selected-area electron diffraction (SAED) pattern of the nanoplate indicated that there are diffraction pattern originated from $1 / 3\{422\}$ reflection (inner small points in Figure 5b) [53]. The spots are displayed due to the stacking faults parallel to the (111) basal plane of nanoplate. Additionally, the cross-sectional HR-TEM image of the Au nanoplate confirmed that the thickness of the Au nanoplates was measured to be only $\sim 15 \mathrm{~nm}$, which is much thinner than the thickness of previous Au nanoplates (average thickness of $100 \mathrm{~nm}$ ) synthesized in a vapor phase at high temperature (Figure 5c). The surface planes of the Au nanoplates were arranged by a Au (111) crystal plane, which corresponded to the TEM results of the Au NPs. Because Au (111) is the most stable crystal plane among the Au crystal planes, the Au NSs were faceted with the Au (111) planes during the synthesis. Previously, it was reported that the disproportionation reaction of $\mathrm{AuCl}$ can be autocatalyzed on a Au surface [44]. Therefore, the growth of the Au nanoplates could be induced by the autocatalyzed reaction of $\mathrm{AuCl}$ under the conditions of a high $\mathrm{AuCl}$ vapor flux. During the Au nanoplate synthesis reaction, $\mathrm{Au}$ nuclei particles may first form on the substrate. Then, the $\mathrm{AuCl}$ vapor collides with the Au nuclei particles and catalyzes the disproportionation of $\mathrm{AuCl}$. Since $\mathrm{AuCl}$ disproportionation is more active 
on the high-energy crystal plane of $\mathrm{Au}$, an enlargement of the $\mathrm{Au}$ (111) plane might be favored, and Au nanoplates may be formed. The proposed synthetic method can provide single-crystalline Au NSs without surfactants and allows us to control the morphology and size of the NSs even at a low temperature of $200{ }^{\circ} \mathrm{C}$; therefore, this method may open new routes for the vapor-phase synthesis of noble metal NSs and their applications.

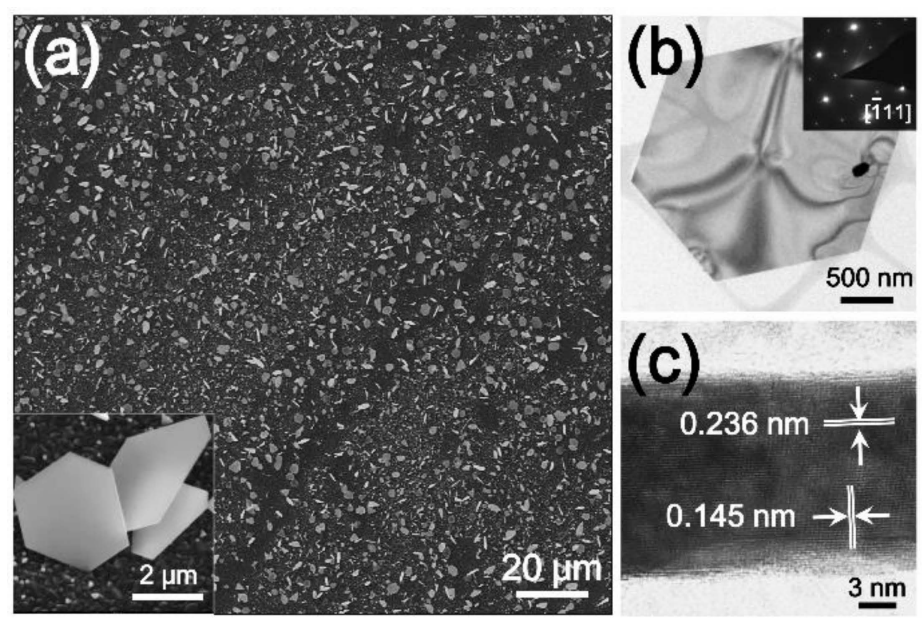

Figure 5. (a) SEM image of free-standing Au nanoplates synthesized on an FTO substrate. The inset is a magnified SEM image of the Au nanoplates; (b) TEM image and selected-area electron diffraction (SAED) pattern (inset) of the Au nanoparticles; and (c) cross-sectional HR-TEM image of the Au nanoplate.

The electrocatalytic oxidation of methanol has been widely studied for the construction of direct methanol fuel cells $[11,54,55]$. During the past decade, Pt has been commonly employed as a catalytic material for the electrooxidation of methanol [56-58]. Although Pt-based catalysts show high catalytic activity for the MOR in acidic media, they often suffer from strong chemisorption of poisoning intermediates during the reaction $[59,60]$. Au-based catalysts exhibit high activity in alkaline media and are free from the formation of poisoning intermediates during the electrooxidation of methanol $[9,44,61,62]$. Therefore, many studies have reported using Au NSs as catalysts for the electrocatalytic oxidation of methanol [10,11,63-65]. Since the Au NPs prepared in this study have the properties necessary to function as an electrocatalyst for the MOR, such as clean surfaces, a direct interface with an FTO substrate, and single crystallinity, we examined the electrocatalytic activity of the Au NPs for the MOR. By employing vapor-phase-grown Au NPs on an FTO substrate as a catalytic electrode, CV curves for the MOR were measured in a $0.1 \mathrm{M} \mathrm{KOH}+1.5 \mathrm{M}$ methanol solution. For comparison, we also prepared a catalytic electrode by dropwise evaporation of commercial colloidal Au NPs on an FTO substrate. Since the size of the Au NPs can significantly influence the catalytic activity, two kinds of Au NPs were prepared with the same average diameter of $20 \mathrm{~nm}$. Additionally, a bare FTO substrate was tested as an electrode to verify that the bare FTO substrate shows no electrocatalytic activity for the MOR (Figure S2). The red line in Figure 6a is the CV curve for the MOR with the vapor-phase-grown Au NPs, and the blue line is the CV curve for the commercial Au NPs. The inset is a magnified image of the CV curve of the commercial Au NPs. The oxidation current density and onset potential for the MOR clearly indicate the outstanding electrocatalytic activity of the vapor-phase-grown Au NPs. The oxidation current density of the Au NPs was calculated by dividing the measured currents by the electrochemical active surface areas (ECSAs) of the electrodes [66]. The ECSAs of the vapor-phase grown and commercial Au NPs were obtained from the CV curves in a $0.1 \mathrm{M} \mathrm{KOH}$ solution (Figure S3). It is noteworthy that the oxidation current density of the vapor-phase-grown Au NPs $\left(14.65 \mathrm{~mA} / \mathrm{cm}^{2}\right)$ was 33 times higher than that of the commercial Au NPs $\left(0.44 \mathrm{~mA} / \mathrm{cm}^{2}\right)$. Furthermore, the vapor-phase-grown Au NPs showed an approximately $0.15 \mathrm{~V}$ lower 
onset potential than the commercial Au NPs, meaning that the oxidation of methanol started earlier when the vapor-phase-grown Au NPs were used.

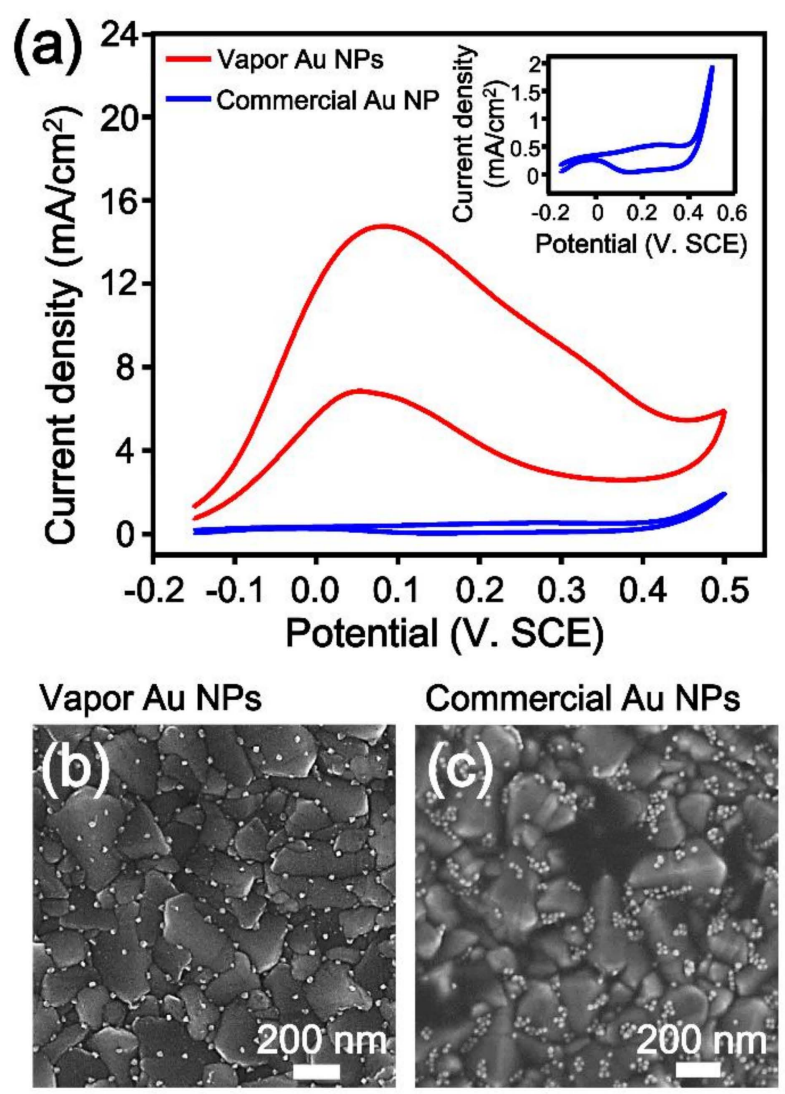

Figure 6. (a) Cyclic voltammetry (CV) curves obtained with vapor-phase-grown Au NP electrodes (red) and commercial Au NP electrodes (blue) in a solution of $0.1 \mathrm{M} \mathrm{KOH}+1.5 \mathrm{M}$ methanol (scan rate $=50 \mathrm{mV} / \mathrm{s})$. Inset is the magnified CV curve for commercial Au NPs; $(\mathbf{b}, \mathbf{c})$ SEM images of $(\mathbf{b})$ vapor-phase-grown Au NP electrodes and (c) commercial Au NP electrodes after the CV measurements. The vapor-phase-grown Au NPs were well dispersed on the FTO substrate, but the commercial Au NPs were slightly aggregated.

After the CV measurements, SEM images of catalytic electrodes were obtained (Figure $6 \mathrm{~b}, \mathrm{c})$. The vapor-phase-grown Au NPs were well dispersed on an FTO substrate, but the commercial Au NPs were slightly aggregated. The agglomeration would contribute to the low electrocatalytic activity of the commercial Au NPs $[67,68]$. To the best of our knowledge, the oxidation current density of $14.65 \mathrm{~mA} / \mathrm{cm}^{2}$ obtained in this experiment is the highest value among those measured in the same media using Au-based electrodes, including self-supported nanoporous Au film electrodes [11], polycrystalline Au electrodes [13], and nanoporous Au electrodes prepared by dealloying Au-Ag [10]. The excellent catalytic activity of the Au NPs can be attributed to the combination of their clean surfaces [21,728, facets well-arranged by the $\mathrm{Au}(111)$ plane $[69,70]$, and intimate contact with the FTO substrate. Consequently, we expect that this Au NS-based electrode can be a versatile tool for various catalytic and electrochemical applications.

\section{Conclusions}

In conclusion, we report the low-temperature vapor-phase synthesis of single-crystalline Au NSs on a conductive substrate and their electrocatalytic application to the MOR. The use of $\mathrm{AuCl}$ as a precursor enabled the synthesis of Au NSs at temperatures below $200{ }^{\circ} \mathrm{C}$ through the disproportionation reaction of $\mathrm{AuCl}$. In this method, Au nanoplates and $\mathrm{Au}$ NPs can be selectively synthesized by adjusting 
the location of the substrate. Moreover, the size of the Au NPs is controllable by varying the reaction temperature. The SEM, TEM, and XPS analyses elucidated the growth mechanism of the Au NSs in the low-temperature vapor phase. Surprisingly, the vapor-phase-grown Au NPs had an oxidation current density of $14.65 \mathrm{~mA} / \mathrm{cm}^{2}$ for the electrocatalytic MOR. This value is 33 times higher than that obtained from commercial Au NPs. Additionally, the vapor-phase-grown Au NPs showed a $0.15 \mathrm{~V}$ lower onset potential than the commercial Au NPs, which indicates the exceptional catalytic performance of the vapor-phase-grown Au NP electrode. We anticipate that this new synthetic approach could expand vapor-phase synthesis of noble metal NSs and their applications to a variety of electrocatalytic or electrochemical reactions.

Supplementary Materials: The following are available online at http://www.mdpi.com/2079-4991/9/4/595/s1; Figure S1: XRD spectrum of the Au NPs synthesized on an FTO substrate, Figure S2: CV curves obtained with a bare FTO substrate in the absence (blue) and presence (red) of $1.5 \mathrm{M}$ methanol in $0.1 \mathrm{M} \mathrm{KOH}$ (scan rate $=50 \mathrm{mV} / \mathrm{s}$ ), Figure S3: CV curves obtained with vapor-phase-grown Au NP electrodes (red) and commercial Au NP electrode (blue) in a solution of $0.1 \mathrm{M} \mathrm{KOH}$ (scan rate $=50 \mathrm{mV} / \mathrm{s}$ ).

Author Contributions: S.Y. takes the lead through the whole experiments. K.P. performed the CV measurements. B.K. and T.K. conceived of the idea and supervised the project. S.Y. and T.K. mainly wrote the manuscript and all authors provided feedback and helped the completion of the final manuscript.

Funding: This research received no external funding.

Acknowledgments: This research was supported by the Basic Science Research Program through the National Research Foundation of Korea (NRF) funded by the Ministry of Science and ICT (MSIT) (NRF-2019R1C1C1006867), the Center for BioNano Health-Guard funded by the MSIT of Korea as Global Frontier Project (H-GUARD_2013M3A6B2078950), the Bio and Medical Technology Development Program of the NRF funded by MSIT of Korea (NRF-2018M3A9E2022821), the First-Mover Program for Accelerating Disruptive Technology Development through the NRF funded by MSIT of Korea (NRF-2018M3C1B9069834), and KRIBB initiative Research Program.

Conflicts of Interest: The authors declare no conflict of interest.

\section{References}

1. Love, J.C.; Estroff, L.A.; Kriebel, J.K.; Nuzzo, R.G.; Whitesides, G.M. Self-assembled monolayers of thiolates on metals as a form of nanotechnology. Chem. Rev. 2005, 105, 1103-1170. [CrossRef] [PubMed]

2. Cantale, V.; Simeone, F.C.; Gambari, R.; Rampi, M.A. Gold nano-islands on FTO as plasmonic nanostructures for biosensors. Sens. Actuator B 2011, 152, 206-213.

3. Diaz-Morales, O.; Calle-Vallejo, F.; de Munck, C.; Koper, M.T. Electrochemical water splitting by gold: Evidence for an oxide decomposition mechanism. Chem. Sci. 2013, 4, 2334-2343. [CrossRef]

4. Al-Harbi, E.; Aziz, M.; Oyama, M.; El-Naggar, A.; AlZayed, N.; Wojciechowski, A.; Kityk, I. Gold nanoparticles deposited on fluorine-doped tin oxide substrates as materials for laser operated optoelectronic devices. J. Mater. Sci. Mater. Electron. 2013, 24, 2422-2425. [CrossRef]

5. Talley, C.E.; Jackson, J.B.; Oubre, C.; Grady, N.K.; Hollars, C.W.; Lane, S.M.; Huser, T.R.; Nordlander, P.; Halas, N.J. Surface-enhanced Raman scattering from individual Au nanoparticles and nanoparticle dimer substrates. Nano Lett. 2005, 5, 1569-1574. [CrossRef]

6. Rodriguez, P.; Kwon, Y.; Koper, M.T. The promoting effect of adsorbed carbon monoxide on the oxidation of alcohols on a gold catalyst. Nat. Chem. 2012, 4, 177. [CrossRef]

7. Luo, J.; Lou, Y.; Maye, M.M.; Zhong, C.-J.; Hepel, M. An EQCN assessment of electrocatalytic oxidation of methanol at nanostructured Au-Pt alloy nanoparticles. Electrochem. Commun. 2001, 3, 172-176. [CrossRef]

8. Hernández, J.; Solla-Gullón, J.; Herrero, E.; Aldaz, A.; Feliu, J.M. Methanol oxidation on gold nanoparticles in alkaline media: Unusual electrocatalytic activity. Electrochim. Acta 2006, 52, 1662-1669. [CrossRef]

9. Borkowska, Z.; Tymosiak-Zielinska, A.; Nowakowski, R. High catalytic activity of chemically activated gold electrodes towards electro-oxidation of methanol. Electrochim. Acta 2004, 49, 2613-2621. [CrossRef]

10. Zhang, J.; Liu, P.; Ma, H.; Ding, Y. Nanostructured porous gold for methanol electro-oxidation. J. Phys. Chem. C 2007, 111, 10382-10388. [CrossRef]

11. Yu, C.; Jia, F.; Ai, Z.; Zhang, L. Direct oxidation of methanol on self-supported nanoporous gold film electrodes with high catalytic activity and stability. Chem. Mater. 2007, 19, 6065-6067. [CrossRef] 
12. Yan, S.; Zhang, S.; Lin, Y.; Liu, G. Electrocatalytic performance of gold nanoparticles supported on activated carbon for methanol oxidation in alkaline solution. J. Phys. Chem. C 2011, 115, 6986-6993. [CrossRef]

13. Jena, B.K.; Raj, C.R. Synthesis of flower-like gold nanoparticles and their electrocatalytic activity towards the oxidation of methanol and the reduction of oxygen. Langmuir 2007, 23, 4064-4070. [CrossRef] [PubMed]

14. Negishi, Y.; Nakazaki, T.; Malola, S.; Takano, S.; Niihori, Y.; Kurashige, W.; Yamazoe, S.; Tsukuda, T.; Häkkinen, H. A critical size for emergence of nonbulk electronic and geometric structures in dodecanethiolate-protected Au clusters. J. Am. Chem. Soc. 2015, 137, 1206-1212. [CrossRef] [PubMed]

15. Tang, Y.; Cheng, W. Nanoparticle-modified electrode with size-and shape-dependent electrocatalytic activities. Langmuir 2013, 29, 3125-3132. [CrossRef] [PubMed]

16. Wang, J.; Gong, J.; Xiong, Y.; Yang, J.; Gao, Y.; Liu, Y.; Lu, X.; Tang, Z. Shape-dependent electrocatalytic activity of monodispersed gold nanocrystals toward glucose oxidation. Chem. Commun. 2011, 47, 6894-6896. [CrossRef]

17. Zhu, M.; Lei, B.; Ren, F.; Chen, P.; Shen, Y.; Guan, B.; Du, Y.; Li, T.; Liu, M. Branched Au nanostructures enriched with a uniform facet: Facile synthesis and catalytic performances. Sci. Rep. 2014, 4, 5259. [CrossRef]

18. Park, J.Y.; Renzas, J.; Hsu, B.B.; Somorjai, G.A. Interfacial and chemical properties of $\mathrm{Pt} / \mathrm{TiO}_{2}, \mathrm{Pd} / \mathrm{TiO}_{2}$, and $\mathrm{Pt} / \mathrm{GaN}$ catalytic nanodiodes influencing hot electron flow. J. Phys. Chem. C 2007, 111, 15331-15336. [CrossRef]

19. Park, J.Y.; Renzas, J.; Contreras, A.; Somorjai, G.A. The genesis and importance of oxide-metal interface controlled heterogeneous catalysis; the catalytic nanodiode. Top. Catal. 2007, 46, 217-222. [CrossRef]

20. Donoeva, B.G.; Ovoshchnikov, D.S.; Golovko, V.B. Establishing a Au nanoparticle size effect in the oxidation of cyclohexene using gradually changing Au catalysts. ACS Catal. 2013, 3, 2986-2991. [CrossRef]

21. Elliott, E.W., III; Glover, R.D.; Hutchison, J.E. Removal of thiol ligands from surface-confined nanoparticles without particle growth or desorption. ACS Nano 2015, 9, 3050-3059. [CrossRef] [PubMed]

22. Muglali, M.I.; Bashir, A.; Rohwerder, M. A study on oxygen reduction inhibition at pyridine-terminated self assembled monolayer modified Au(111) electrodes. Phys. Status Solidi (A) 2010, 207, 793-800. [CrossRef]

23. Niu, Z.; Li, Y. Removal and Utilization of Capping Agents in Nanocatalysis. Chem. Mater. 2014, 26, 72-83. [CrossRef]

24. Aliaga, C.; Park, J.Y.; Yamada, Y.; Lee, H.S.; Tsung, C.-K.; Yang, P.; Somorjai, G.A. Sum Frequency Generation and Catalytic Reaction Studies of the Removal of Organic Capping Agents from Pt Nanoparticles by UV-Ozone Treatment. J. Phys. Chem. C 2009, 113, 6150-6155. [CrossRef]

25. Chen, Y.; Fernandes, A.A.; Erbe, A. Control of shape and surface crystallography of gold nanocrystals for electrochemical applications. Electrochim. Acta 2013, 113, 810-816. [CrossRef]

26. Grzelczak, M.; Pérez-Juste, J.; Mulvaney, P.; Liz-Marzán, L.M. Shape control in gold nanoparticle synthesis. Chem. Soc. Rev. 2008, 37, 1783-1791. [CrossRef]

27. Nikoobakht, B.; El-Sayed, M.A. Preparation and Growth Mechanism of Gold Nanorods (NRs) Using Seed-Mediated Growth Method. Chem. Mater. 2003, 15, 1957-1962. [CrossRef]

28. Cargnello, M.; Chen, C.; Diroll, B.T.; Doan-Nguyen, V.V.T.; Gorte, R.J.; Murray, C.B. Efficient Removal of Organic Ligands from Supported Nanocrystals by Fast Thermal Annealing Enables Catalytic Studies on Well-Defined Active Phases. J. Am. Chem. Soc. 2015, 137, 6906-6911. [CrossRef]

29. Ansar, S.M.; Ameer, F.S.; Hu, W.; Zou, S.; Pittman, C.U.; Zhang, D. Removal of Molecular Adsorbates on Gold Nanoparticles Using Sodium Borohydride in Water. Nano Lett. 2013, 13, 1226-1229. [CrossRef]

30. Xiao, X.; Pan, S.; Jang, J.S.; Fan, F.-R.F.; Bard, A.J. Single Nanoparticle Electrocatalysis: Effect of Monolayers on Particle and Electrode on Electron Transfer. J. Phys. Chem. C 2009, 113, 14978-14982. [CrossRef]

31. Horibe, T.; Zhang, J.; Oyama, M. Effects of Capping Reagents on the Electron Transfer Reactions on Gold Nanoparticle-Attached Indium Tin Oxide Electrodes. Electroanalysis 2007, 19, 847-852. [CrossRef]

32. Nakaso, K.; Han, B.; Ahn, K.H.; Choi, M.; Okuyama, K. Synthesis of non-agglomerated nanoparticles by an electrospray assisted chemical vapor deposition (ES-CVD) method. J. Aerosol Sci. 2003, 34, 869-881. [CrossRef]

33. Goodman, D.W. Model Studies in Catalysis Using Surface Science Probes. Chem. Rev. 1995, 95, 523-536. [CrossRef]

34. Gong, J. Structure and Surface Chemistry of Gold-Based Model Catalysts. Chem. Rev. 2012, 112, $2987-3054$ [CrossRef] [PubMed] 
35. Yoo, Y.; Lee, H.; Lee, H.; Lee, M.; Yang, S.; Hwang, A.; Kim, S.-I.; Park, J.Y.; Choo, J.; Kang, T.; et al. Surfactant-Free Vapor-Phase Synthesis of Single-Crystalline Gold Nanoplates for Optimally Bioactive Surfaces. Chem. Mater. 2017, 29, 8747-8756. [CrossRef]

36. Okumura, M.; Nakamura, S.; Tsubota, S.; Nakamura, T.; Azuma, M.; Haruta, M. Chemical vapor deposition of gold on $\mathrm{Al}_{2} \mathrm{O}_{3}, \mathrm{SiO}_{2}$, and $\mathrm{TiO}_{2}$ for the oxidation of $\mathrm{CO}$ and of $\mathrm{H}_{2}$. Catal. Lett. 1998, 51, 53-58. [CrossRef]

37. Jen Cho, S.; Suri, A.; Mei, X.; Ouyang, J. In situ deposition of gold nanostructures with well-defined shapes on unfunctionalized reduced graphene oxide through chemical reduction of a dry gold precursor with ethylene glycol vapor. RSC Adv. 2013, 3, 1201-1209. [CrossRef]

38. Chen, Y.; Tian, X.; Zeng, W.; Zhu, X.; Hu, H.; Duan, H. Vapor-phase preparation of gold nanocrystals by chloroauric acid pyrolysis. J. Colloid Interface Sci. 2015, 439, 21-27. [CrossRef]

39. Kang, T.; Min Yoo, S.; Kang, M.; Lee, H.; Kim, H.; Lee, S.Y.; Kim, B. Single-step multiplex detection of toxic metal ions by Au nanowires-on-chip sensor using reporter elimination. Lab Chip 2012, 12, 3077-3081. [CrossRef]

40. Yoo, Y.; Seo, K.; Han, S.; Varadwaj, K.S.K.; Kim, H.Y.; Ryu, J.H.; Lee, H.M.; Ahn, J.P.; Ihee, H.; Kim, B. Steering Epitaxial Alignment of $\mathrm{Au}, \mathrm{Pd}$, and AuPd Nanowire Arrays by Atom Flux Change. Nano Lett. 2010, 10, 432-438. [CrossRef]

41. Makela, M.; Hatanpaa, T.; Mizohata, K.; Raisanen, J.; Ritala, M.; Leskela, M. Thermal Atomic Layer Deposition of Continuous and Highly Conducting Gold Thin Films. Chem. Mater. 2017, 29, 6130-6136.

42. Makela, M.; Hatanpaa, T.; Ritala, M.; Leskela, M. Potential gold(I) precursors evaluated for atomic layer deposition. J. Vac. Sci. Technol. A 2017, 35, 01B112. [CrossRef]

43. Griffiths, M.B.; Koponen, S.E.; Mandia, D.J.; McLeod, J.F.; Coyle, J.P.; Sims, J.J.; Giorgi, J.B.; Sirianni, E.R.; Yap, G.P.; Barry, S.T. Surfactant directed growth of gold metal nanoplates by chemical vapor deposition. Chem. Mater. 2015, 27, 6116-6124. [CrossRef]

44. Gammons, C.H.; Yu, Y.; Williams-Jones, A.E. The disproportionation of gold(I) chloride complexes at 25 to $200{ }^{\circ} \mathrm{C}$. Geochim. Cosmochim. Acta 1997, 61, 1971-1983. [CrossRef]

45. Wang, X.; Chen, Y.; Zhu, X.; Li, Z.; Shang, Z.; Duan, H. Vapor-phase preparation of single-crystalline thin gold microplates using $\mathrm{HAuCl}_{4}$ as the precursor for plasmonic applications. RSC Adv. 2016, 6, 74937-74943. [CrossRef]

46. Patnaik, P. Handbook of Inorganic Chemicals; McGraw-Hill: New York, NY, USA, 2003.

47. Lu, X.; Tuan, H.Y.; Korgel, B.A.; Xia, Y. Facile synthesis of gold nanoparticles with narrow size distribution by using $\mathrm{AuCl}$ or $\mathrm{AuBr}$ as the precursor. Chem. Eur. J. 2008, 14, 1584-1591. [CrossRef] [PubMed]

48. Bergamini, G.; Ceroni, P.; Balzani, V.; Gingras, M.; Raimundo, J.-M.; Morandi, V.; Merli, P.G. Synthesis of small gold nanoparticles: $\mathrm{Au}(\mathrm{i})$ disproportionation catalyzed by a persulfurated coronene dendrimer. Chem. Commun. 2007, 40, 4167-4169. [CrossRef]

49. Hee Shin, D.; Min Kim, J.; Wook Jang, C.; Hwan Kim, J.; Kim, S.; Choi, S.-H. Annealing effects on the characteristics of AuCl3-doped graphene. J. App. Phys. 2013, 113, 064305. [CrossRef]

50. Kim, S.M.; Kim, K.K.; Jo, Y.W.; Park, M.H.; Chae, S.J.; Duong, D.L.; Yang, C.W.; Kong, J.; Lee, Y.H. Role of anions in the $\mathrm{AuCl}_{3}$-doping of carbon nanotubes. Acs Nano 2011, 5, 1236-1242. [CrossRef] [PubMed]

51. Parkhomenko, R.; Morozova, B.N.; Zharkova, I.G.; Shubin, V.Y.; Trubin, S.; Kriventsov, V.; Kuchumov, M.B.; Koretskaya, P.T.; Igumenov, I. Deposition of Au Thin Films and Nanoparticles by MOCVD. Chem. Vap. Depos. 2012, 18, 336-342. [CrossRef]

52. Ali Umar, A.; Oyama, M. Formation of Gold Nanoplates on Indium Tin Oxide Surface: Two-dimensional Crystal Growth from Gold Nanoseed Particles in the Presence of Poly (vinylpyrrolidone). Cryst. Growth Des. 2006, 6, 818-821. [CrossRef]

53. Germain, V.; Li, J.; Ingert, D.; Wang, Z.L.; Pileni, M.P. Stacking Faults in Formation of Silver Nanodisks. J. Phys. Chem. B 2003, 107, 8712-8720. [CrossRef]

54. Kwon, T.; Jun, M.; Kim, H.Y.; Oh, A.; Park, J.; Baik, H.; Joo, S.H.; Lee, K. Vertex-Reinforced PtCuCo Ternary Nanoframes as Efficient and Stable Electrocatalysts for the Oxygen Reduction Reaction and the Methanol Oxidation Reaction. Adv. Funct. Mater. 2018, 28, 1706440. [CrossRef]

55. Huang, H.; Yang, S.; Vajtai, R.; Wang, X.; Ajayan, P.M. Pt-decorated 3D architectures built from graphene and graphitic carbon nitride nanosheets as efficient methanol oxidation catalysts. Adv. Mater. 2014, 26, 5160-5165. [CrossRef] [PubMed] 
56. Yang, L.; Yang, W.; Cai, Q. Well-Dispersed PtAu Nanoparticles Loaded into Anodic Titania Nanotubes: A High Antipoison and Stable Catalyst System for Methanol Oxidation in Alkaline Media. J. Phys. Chem. C 2007, 111, 16613-16617. [CrossRef]

57. Wang, J.; Zhang, X.-B.; Wang, Z.-L.; Wang, L.-M.; Xing, W.; Liu, X. One-step and rapid synthesis of "clean" and monodisperse dendritic Pt nanoparticles and their high performance toward methanol oxidation and p-nitrophenol reduction. Nanoscale 2012, 4, 1549-1552. [CrossRef]

58. Hsu, C.-H.; Liao, H.-Y.; Wu, Y.-F.; Kuo, P.-L. Benzylamine-Assisted Noncovalent Exfoliation of Graphite-Protecting Pt Nanoparticles Applied as Catalyst for Methanol Oxidation. ACS Appl. Mater. Interfaces 2011, 3, 2169-2172. [CrossRef]

59. Siyu, H.; Ying, C. Electrochemical Catalytic Oxidation Performance of a Nanoporous Gold Electrode. Rare Met. Mater. Eng. 2015, 44, 2156-2158. [CrossRef]

60. Kita, H.; Ye, S.; Sugimura, K. Effects of adsorbed CO on the electrode reactions at a platinum electrode. J. Electroanal. Chem. Interfacial Electrochem. 1991, 297, 283-296. [CrossRef]

61. Kwon, Y.; Lai, S.C.; Rodriguez, P.; Koper, M.T. Electrocatalytic oxidation of alcohols on gold in alkaline media: Base or gold catalysis? J. Am. Chem. Soc. 2011, 133, 6914-6917. [CrossRef]

62. Ketchie, W.C.; Fang, Y.-L.; Wong, M.S.; Murayama, M.; Davis, R.J. Influence of gold particle size on the aqueous-phase oxidation of carbon monoxide and glycerol. J. Catal. 2007, 250, 94-101. [CrossRef]

63. Zope, B.N.; Hibbitts, D.D.; Neurock, M.; Davis, R.J. Reactivity of the Gold/Water Interface during Selective Oxidation Catalysis. Science 2010, 330, 74. [CrossRef] [PubMed]

64. Pedireddy, S.; Lee, H.K.; Tjiu, W.W.; Phang, I.Y.; Tan, H.R.; Chua, S.Q.; Troadec, C.; Ling, X.Y. One-step synthesis of zero-dimensional hollow nanoporous gold nanoparticles with enhanced methanol electrooxidation performance. Nat. Commun. 2014, 5, 4947. [CrossRef] [PubMed]

65. Nagaraju, D.; Lakshminarayanan, V. Electrochemically grown mesoporous gold film as high surface area material for electro-oxidation of alcohol in alkaline medium. J. Phys. Chem. C 2009, 113, 14922-14926. [CrossRef]

66. Trasatti, S.; Petrii, O. Real surface area measurements in electrochemistry. Pure Appl. Chem. 1991, 63, 711-734. [CrossRef]

67. Daniel, M.-C.; Astruc, D. Gold nanoparticles: Assembly, supramolecular chemistry, quantum-size-related properties, and applications toward biology, catalysis, and nanotechnology. Chem. Rev. 2004, 104, 293-346. [CrossRef]

68. Lou, Y.; Maye, M.M.; Han, L.; Luo, J.; Zhong, C.-J. Gold-platinum alloy nanoparticle assembly as catalyst for methanol electrooxidation. Chem. Commun. 2001, 473-474. [CrossRef]

69. Jebaraj, A.J.J.; de Godoi, D.R.M.; Scherson, D.A. Pronounced Surface Sensitivity of Hydroxylamine Oxidation on Gold Single-Crystal Electrodes in Acidic and Neutral Aqueous Solutions. Acs Catal. 2012, 2, 911-915. [CrossRef]

70. Chen, Y.; Schuhmann, W.; Hassel, A.W. Electrocatalysis on gold nanostructures: Is the $\{110\}$ facet more active than the $\left\{\begin{array}{lll}1 & 1 & 1\end{array}\right\}$ facet? Electrochem. Commun. 2009, 11, 2036-2039. [CrossRef]

(C) 2019 by the authors. Licensee MDPI, Basel, Switzerland. This article is an open access article distributed under the terms and conditions of the Creative Commons Attribution (CC BY) license (http://creativecommons.org/licenses/by/4.0/). 